\title{
Meta-analysis of differences in Constant-Murley scores for three mid-shaft clavicular fracture treatments
}

\author{
Wei Jiang ${ }^{1}$, Hua Wang ${ }^{1}$, Yu-Sheng Li ${ }^{2}$, Tian-Jian Zhou ${ }^{1}$ and Xin-Jia Hu ${ }^{1}$ \\ ${ }^{1}$ Department of Bone and Joint, Shenzhen People's Hospital, 2nd Clinical Medical College of Jinan University, Shenzhen \\ 518020, China \\ ${ }^{2}$ Department of Orthopedics, Xiangya Hospital, Central South University, Changsha 410008, China
}

Correspondence to: Xin-Jia Hu, email: xinjj_hh@163.com

Keywords: clavicular fracture, non-operative treatment, plate fixation, intramedullary pin fixation, Constant-Murley score Received: October 27, $2016 \quad$ Accepted: May 19, $2017 \quad$ Published: June 12, 2017

Copyright: Jiang et al. This is an open-access article distributed under the terms of the Creative Commons Attribution License 3.0 (CC BY 3.0), which permits unrestricted use, distribution, and reproduction in any medium, provided the original author and source are credited.

\section{ABSTRACT}

There is no consensus on the optimal treatment for mid-shaft clavicular fracture. We conducted a meta-analysis to compare the effectiveness of non-operative treatment, plate fixation, and intramedullary pin fixation in terms of the ConstantMurley Score (CMS) for treatment of mid-shaft clavicular fracture. Comprehensive search of the Embase, Cochrane Library and PubMed was conducted to retrieve relevant randomized controlled trials (RCTs). A random-effect network meta-analysis was conducted within a Bayesian framework using Markov Chain Monte Carlo (MCMC) in OpenBUGS 3.2.2. Differences in CMS among the three treatments analyzed were evaluated with weighted mean difference (WMD) and surface under the cumulative ranking curves (SUCRA). Eleven studies met our inclusion criteria and were included in our network meta-analysis. Our results revealed that in terms of CMS followed-up for six months, the efficacies of plate fixation and intramedullary pin fixation were higher than non-operative treatment (plate fixation: WMD = 4.70, 95\% CI = 1.21 7.83; intramedullary pin fixation: WMD $=6.71,95 \% \mathrm{CI}=3.20 \sim 10.39$ ), and intramedullary pin fixation had better efficacy than plate fixation, had better efficacy. However, no differences were found between the efficacies of the three treatments in pairwise comparisons with respect to CMS followed-up for six weeks, three months, 12 months and 24 months. In addition, the cluster analysis showed that intramedullary pin fixation had the best efficacy for patients with mid-shaft CF, followed by plate fixation and non-operative treatment. These analyses suggest intramedullary pin fixation may be the optimal therapeutic approach for mid-shaft clavicular fracture patients.

\section{INTRODUCTION}

The clavicle, located directly above the first rib, is one of the most commonly fractured bones, accounting for about $3 \% \sim 5 \%$ of all fractures [1]. Clavicular fracture (CF) generally occurs in the mid-shaft (81\%), while lateral $(17 \%)$ together with medial fractures $(2 \%)$ are less frequently [2]. The incidence of mid-shaft $\mathrm{CF}$ is approximately 29 64 per 100,000 persons annually; additionally, children have significantly higher rates of CF compared to adults [3, 4]. Typically, mid-shaft $\mathrm{CF}$ results from falls, sport injuries and motor vehicle accidents. The main reasons for mid-shaft $\mathrm{CF}$ are falling onto outstretched hands, a direct hit to the clavicle, and direct falls on the shoulder [5]. Non-surgical treatment options are the first line of intervention for mid-shaft CF treatment, and surgery is considered when other treatments fail, or as a corrective intervention [6]. However, serious complications can occur in mid-shaft CF patients after treatment, including nonunion or re-fracture along with malunion, which further results in chronic pain, weakness, decreased range of motion and cosmetic deformity [4]. Thus, identifying the most efficacious and safest approach for mid-shaft CF treatment would help increase the likelihood of optimal restoration of shoulder stability and function for patients [7].

Non-operative traditional treatments (mostly sling or figure-of-eight bandage) have been used to treat 
mid-shaft CF, even when the clavicle is substantially displaced [8]. However, studies have shown that with higher rates of nonunion, malunion, and patient dissatisfaction, the outcome of non-operative treatments is not as satisfactory as previously thought [9]. Currently, surgical options of plate fixation and intramedullary pin fixation are commonly applied in patients with mid-shaft CF [10]. Pujalte GG proposed that when compared with non-operative treatment, mid-shaft $\mathrm{CF}$ treated with plate fixation may lead to improved functional outcome with a lower rate of malunion and nonunion [11]. Plate fixation entails a large operative wound and stripping of soft tissue, and is associated with complications, such as nonunion, infection, wound breakdown, and local numbness with loss of reduction [12]. Recently, surgeons have attempted to use intramedullary pin fixation to treat mid-shaft $\mathrm{CF}$, but this approach also yielded rates of nonunion and infection similar to those reported for plate fixation [5]. Potential limitations include hardware migration or failure, re-fracture after hardware removal, painful prominent hardware, and the development of nonunion [13]. Since no consensus has been reached on the optimal treatment for mid-shaft CF, measuring the relative efficacies of different treatments procedures could help to improve the surgical outcomes and experiences of patients $[14,15]$.

Traditional meta-analyses combine the results of homogeneous studies conducted on the same topic, and it is not feasible to compare more than two interventions at the same time [16]. However, a network meta-analysis can indirectly compare three or more procedures, using a common comparator, when a head-to-head trial is not available, and can also simultaneously compare several intervention methods by combining direct and indirect comparisons $[17,18]$. Therefore, to help establish the optimal treatment for patients with mid-shaft $\mathrm{CF}$, we performed a network meta-analysis based on previous studies to compare the efficacies of non-operative treatment, plate fixation, and intramedullary pin fixation in terms of the Constant-Murley Score (CMS).

\section{RESULTS}

\section{Baseline characteristics of included studies}

Our electronic literature search broadly identified a total of 189 potentially pertinent studies. After reading the titles and abstracts, we excluded 44 duplicates. The remaining 145 articles were further evaluated with 134 articles being removed for following reasons: 36 for monotherapy of mid-shaft $\mathrm{CF}, 53$ for no relation to research topic, 21 for proceedings and abstracts, 13 for non-human studies, and one for low degree of association of outcomes investigated. In the end, a total of 11 studies, published between 2007 and 2015, met our predetermined inclusion criteria, and were thus incorporated into our network meta-analysis $[1,10,19-27]$. Taken together, these 10 studies included 721 mid-shaft CF patients (non-operative treatment: $n=184$; plate fixation: $n=256$; intramedullary pin fixation: $n=281$ ). All of the included studies were two-arm trials, including 11 comparisons. The baseline characteristics of included studies and the PEDro scale are displayed in Table 1 and Figure 1, respectively.

\section{Pairwise meta-analysis}

The efficacies of three treatment methods for midshaft CF were evaluated with direct-paired comparisons. The results indicated that the efficacy of non-operative treatment for mid-shaft CF was relatively poor compared with plate fixation in terms of CMS followed-up for six weeks (WMD $=-9.70,95 \% \mathrm{CI}=-17.65 \sim-1.75$ ) while no difference was found for the efficacies in comparison between plate fixation and intramedullary pin fixation $(\mathrm{WMD}=-2.00,95 \% \mathrm{CI}=-10.67 \sim 6.68)$ (Supplementary Figure 1A). As for the CMS followed-up for three months, our results showed no difference in the direct paired comparisons of non-operative treatment vs. plate fixation and plate fixation vs. intramedullary pin fixation $(\mathrm{WMD}=-1.89,95 \% \mathrm{CI}=-4.37 \sim 0.59$; WMD $=-1.86$, $95 \% \mathrm{CI}=-4.40 \sim 0.67$, respectively) (Supplementary Figure 1B). There was no obvious heterogeneity for comparisons of non-operative treatment vs. plate fixation and plate fixation vs. intramedullary pin fixation with respect to CMS followed-up for six months $\left(I^{2}=0.0 \%, P\right.$ $=0.5789 ; I^{2}=0.0 \%, P=0.5344$, respectively), thus we adopted the fixed-effect model. Additionally, the results of direct paired comparisons showed that compared with plate fixation and intramedullary pin fixation, the efficacy of nonoperative treatment for mid-shaft $\mathrm{CF}$ was relatively poor $(\mathrm{WMD}=-3.45,95 \% \mathrm{CI}=-6.38 \sim-0.51$; WMD $=-9.00$, $95 \% \mathrm{CI}=-13.38 \sim-4.62$, respectively), and the efficacy of plate fixation was relatively poor when compared with intramedullary pin fixation (WMD $=-1.77,95 \% \mathrm{CI}=$ -2.88 -0.66) (Figure 2). For CMS followed-up for 12 months, no difference was found between plate fixation and non-operative treatment $(\mathrm{WMD}=-1.49,95 \% \mathrm{CI}=$ $-7.95 \sim 4.97$ ), and the efficacy of plate fixation was poorer than that of intramedullary pin fixation (WMD $=-2.25$, $95 \% \mathrm{CI}=-4.17 \sim-0.34$ ) (Supplementary Figure 1C). For CMS followed-up for 24 months, the efficacy of nonoperative treatment was poorer than that of intramedullary pin fixation $(\mathrm{WMD}=-3.51,95 \% \mathrm{CI}=-5.05 \sim-1.98)$, and no significant difference was found between plate fixation and intramedullary pin fixation $(\mathrm{WMD}=0.10,95 \% \mathrm{CI}=$ 2.97 3.17) (Supplementary Figure 1D).

\section{Pooled results of network meta-analysis}

\section{Evidence network}

The present network meta-analysis included three kinds of treatments: non-operative treatment, plate fixation and intramedullary pin fixation. In terms of CMS followed- 
Table 1: The baseline characteristics of ten enrolled studies

\begin{tabular}{|c|c|c|c|c|c|c|c|c|c|c|c|c|}
\hline \multirow{2}{*}{ First author } & \multirow{2}{*}{ Year } & \multirow{2}{*}{ Country } & \multicolumn{2}{|c|}{ Interventions } & \multirow{2}{*}{ Total } & \multicolumn{2}{|c|}{ Sample size } & \multicolumn{2}{|c|}{ Gender (M/F) } & \multicolumn{2}{|c|}{ Age (years) } & \multirow{2}{*}{ Follow-up time(weeks/months) } \\
\hline & & & T1 & T2 & & T1 & $\mathbf{T} 2$ & T1 & T2 & T1 & T2 & \\
\hline Lee YS [19] & 2007 & China & B & $\mathrm{C}$ & 62 & 30 & 32 & $13 / 17$ & $13 / 19$ & $56.7(52-59)$ & $60.4(50-81)$ & $6 \mathrm{~m}$ \\
\hline Lee YS [20] & 2008 & China & B & $\mathrm{C}$ & 88 & 32 & 56 & $20 / 12$ & $37 / 19$ & 38.2 & 40.1 & $6 \mathrm{~m}$ \\
\hline Judd DB [10] & 2009 & USA & A & B & 57 & 28 & 29 & $25 / 3$ & $27 / 2$ & $25(17-41)$ & $28(19-40)$ & $3 \mathrm{w}, 6 \mathrm{w}, 3 \mathrm{~m}, 6 \mathrm{~m}, 12 \mathrm{~m}$ \\
\hline Smekal V [1] & 2009 & Austria & A & $\mathrm{C}$ & 60 & 30 & 30 & $26 / 4$ & $26 / 4$ & $39.8 \pm 14.5$ & $35.5 \pm 11.8$ & $6 \mathrm{~m}, 24 \mathrm{~m}$ \\
\hline Ferran NA [21] & 2010 & UK & B & $\mathrm{C}$ & 32 & 15 & 17 & $13 / 2$ & $14 / 3$ & $35.4(16-53)$ & $23.8(13-42)$ & $12 \mathrm{~m}$ \\
\hline Assobhi JE [22] & 2011 & Egypt & B & $\mathrm{C}$ & 38 & 19 & 19 & $17 / 2$ & $16 / 3$ & $32.6 \pm 5.9$ & $30.3 \pm 4.8$ & $6 \mathrm{w}, 3 \mathrm{~m}, 6 \mathrm{~m}, 12 \mathrm{~m}$ \\
\hline Smekal V [23] & 2011 & Austria & A & $\mathrm{C}$ & 112 & 52 & 60 & $44 / 8$ & $54 / 6$ & $38.0 \pm 14.8$ & $36.8 \pm 12.6$ & $24 \mathrm{~m}$ \\
\hline Virtanen KJ [24] & 2012 & Finland & A & B & 60 & 32 & 28 & $28 / 4$ & $24 / 4$ & $33.0 \pm 12.0$ & $41.0 \pm 10.8$ & $3 \mathrm{~m}, 12 \mathrm{~m}$ \\
\hline Narsaria N [25] & 2014 & India & B & $\mathrm{C}$ & 65 & 32 & 33 & $26 / 6$ & $24 / 9$ & $40.2 \pm 11.2$ & $38.9 \pm 9.1$ & $24 \mathrm{~m}$ \\
\hline Saha P [26] & 2014 & India & B & $\mathrm{C}$ & 71 & 37 & 34 & $30 / 7$ & $30 / 4$ & $33.32 \pm 11.84$ & $33.03 \pm 12.64$ & $6 \mathrm{w}, 3 \mathrm{~m}, 6 \mathrm{~m}, 12 \mathrm{~m}, 18 \mathrm{~m}, 24 \mathrm{~m}$ \\
\hline Melean PA [27] & 2015 & Chile & A & B & 76 & 42 & 34 & NR & NR & $37.2 \pm 11.2$ & $38.1 \pm 13.0$ & $3 \mathrm{~m}, 6 \mathrm{~m}, 12 \mathrm{~m}$ \\
\hline
\end{tabular}

T, treatment; M, male; F, female; NR, not report; A, non-operative treatment; B, plate fixation; C, intramedullary pin fixation; m, months; w, weeks.

up for six weeks, the majority of the patients received plate fixation. In this network meta-analysis, the majority of the analyzed studies showed direct comparisons for plate fixation and intramedullary pin fixation (Supplementary Figure 2A). With respect to CMS followed-up for three months, most patients were treated with plate fixation. In this network meta-analysis, most of the analyzed studies showed direct comparisons for non-operative treatment and plate fixation (Supplementary Figure 2B). As for CMS followed-up for six months, most of the patients were treated with plate fixation. In this network metaanalysis, the majority of the studies analyzed showed direct comparisons for plate fixation and intramedullary pin fixation (Figure 3A). In terms of CMS followed-up

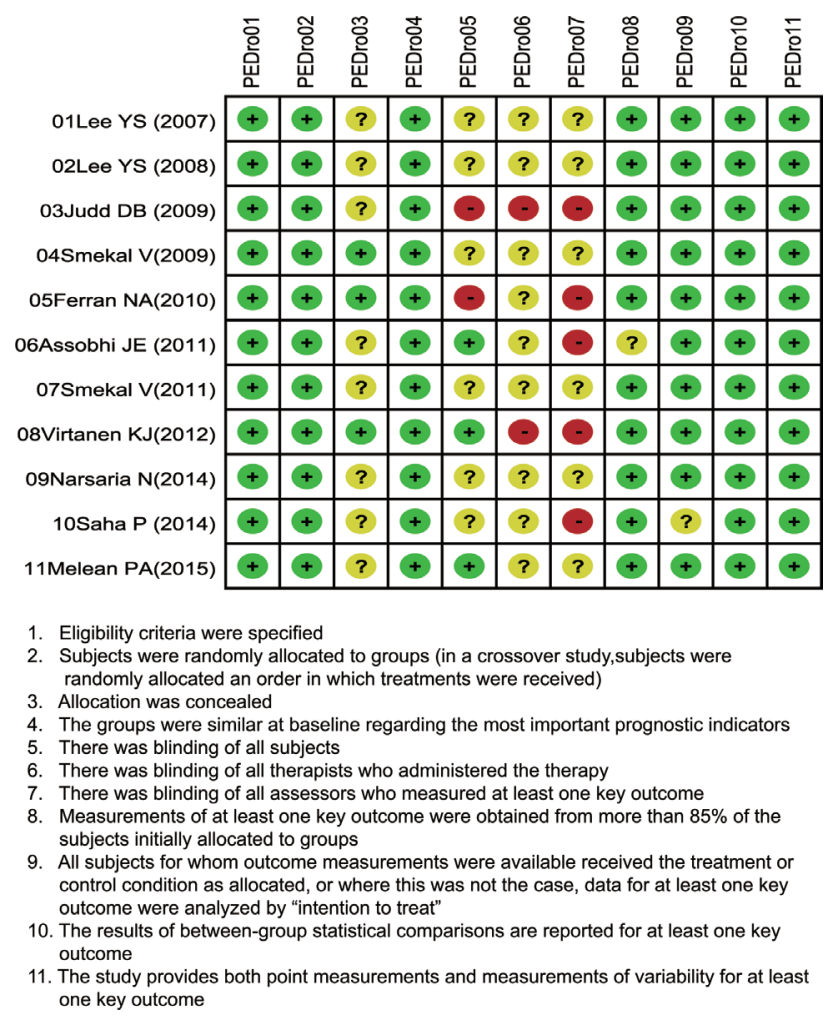

Figure 1: Methodological quality of assessment for included studies from the literature, based on the Physiotherapy Evidence Database (PEDro) scale. 
for 12 months, the majority of patients were treated with plate fixation. In this network meta-analysis, most of the previous studies analyzed showed direct comparisons for non-operative treatment and plate fixation (Supplementary Figure 2C). With respect to CMS followed-up for 24 months, most patients were treated with intramedullary pin fixation. In this network meta-analysis, most of the studies analyzed showed direct comparisons for non-operative treatment and intramedullary pin fixation (Supplementary Figure 2D).

\section{Inconsistency test}

The consistency model was used since the data of CMS followed-up for six weeks, three months, 12 months and 24 months were all non-network data without closedloop. As for the network data of CMS followed-up for six months, the node partition method was used for inconsistency tests. The results showed that all direct and indirect evidence were consistent, and the consistency model was adopted (all $P>0.05$ ) (Figure $3 \mathrm{~B}$ ).

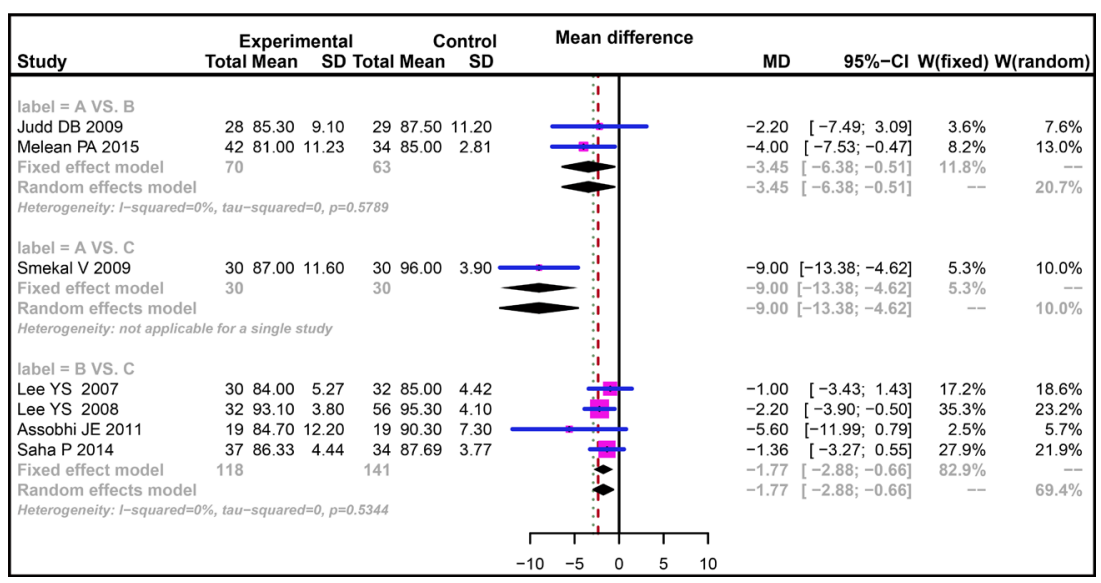

Figure 2: Forest plots comparing the efficacy of three treatments in patients with clavicle fracture in terms of CMS followed-up for six months. (A) Non-operative treatment. (B) Plate fixation. (C) Intramedullary pin fixation. CMS, Constant-Murley Score.
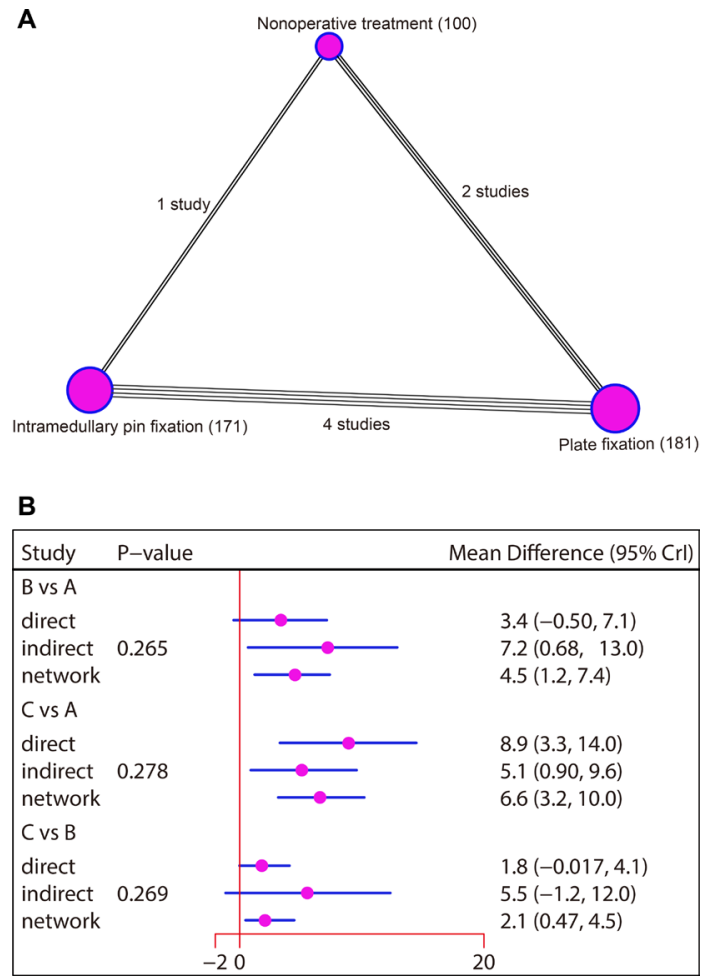

Figure 3: Network diagram and node-splitting method comparing the efficacy of three treatments in patients with clavicle fracture in terms of CMS followed-up for six months. (A) Non-operative treatment. (B) Plate fixation. (C) Intramedullary pin fixation. CMS, Constant-Murley Score. 


\section{Main results of network meta-analysis}

Seven studies reported the efficacies of nonoperative treatment, plate fixation, and intramedullary pin fixation to treat mid-shaft $\mathrm{CF}$ with a follow-up period of six months. Here, our network meta-analysis showed that the efficacies of plate fixation and intramedullary pin fixation were better than that of the non-operative treatment $(\mathrm{WMD}=4.70,95 \% \mathrm{CI}=1.21 \sim 7.83 ; \mathrm{WMD}=6.71,95 \%$ $\mathrm{CI}=3.20 \sim 10.39$, respectively). Compared with plate fixation, mid-shaft $\mathrm{CF}$ patients treated with intramedullary pin fixation had better outcomes (WMD $=2.05,95 \%$ $\mathrm{CI}=0.30 \sim 4.64)$ (Figure 4 and Table 2). Additionally, the efficacies of these three treatments for mid-shaft $\mathrm{CF}$ with follow-up periods of six weeks, three months, 12 months, and 24 months were reported in three, five, six and four studies, respectively. However, our network meta-analysis indicated that there was no difference for the efficacies of these three treatments in terms of CMS in pairwise comparisons (Supplementary Figure 3 and Table 3).

\section{Surface under the cumulative ranking curves (SUCRA)}

As shown in Table 4, the SUCRA value of intramedullary pin fixation was highest with respect to CMS followed-up for six weeks, three months, six months and 12 months (six weeks: $78.0 \%$; three months: 88.5\%; six months: $98.5 \%$; 12 months: $91.0 \%$ ). As for CMS followed-up for 24 months, plate fixation had the highest SUCRA value (86.7\%), followed by pin fixation (76.7\%); The SUCRA value of non-operative treatment was the lowest (six weeks: $8.5 \%$; three months: $12.5 \%$; six months: $0.5 \%$; 12 months: $16.5 \%$; 24 months: $36.7 \%$ ).

\section{Cluster analysis}

Cluster analysis based on the SUCRA values with respect to CMS followed-up for six weeks, three months, six months, 12 months and 24 months revealed that intramedullary pin fixation had the best efficacy for patients with mid-shaft $\mathrm{CF}$, followed by plate fixation and non-operative treatment (Figure 5).

\section{DISCUSSION}

The main results of our network meta-analysis revealed that the efficacy of intramedullary pin fixation in patients with CF was better compared to that of nonoperative treatment and plate fixation in terms of CMS followed-up for six months. It has been previously reported that various problems can arise when mid-shaft CF patients are treated with non-operative treatment, including 1) pain and instability in the first three weeks after injury; 2) difficulty in daily care because of multiple traumas; 3 ) elevated tightness of figure-of-eight bandage leading to phlebostasis of arm veins; and 4) high nonunion rate in cases of severe displacement and high-energy trauma. Thus, an alternative surgical treatment for $\mathrm{CF}$ was recommended [19]. Surgery is increasingly accepted as the

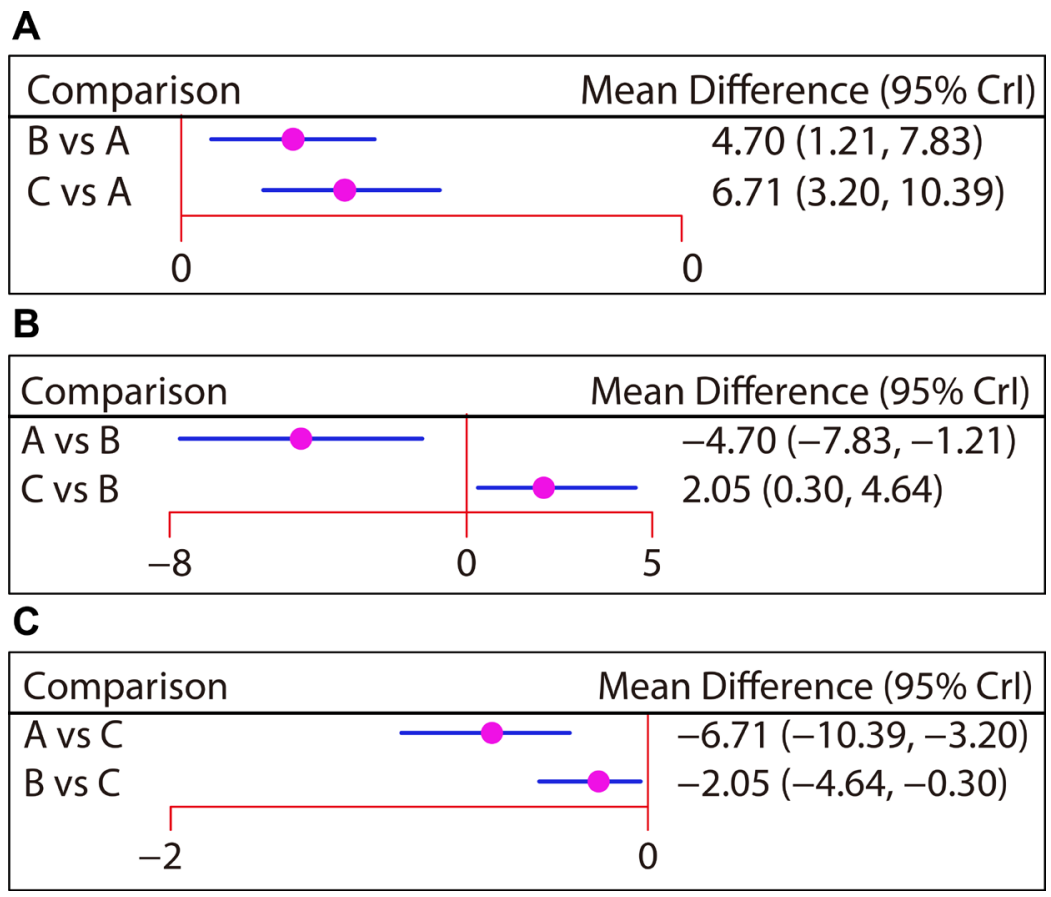

Figure 4: Forest plots of the relationship between efficacy comparisons for three treatments in patients with clavicle fracture in terms of CMS followed-up for six months. (A) Non-operative treatment. (B) Plate fixation. (C) Intramedullary pin fixation. CMS, Constant-Murley Score. 
Table 2: Weighted mean difference and $95 \%$ confidence intervals of three treatment modalities of clavicular fractures patients in terms of the Constant-Murley Score after 6 months

\begin{tabular}{lll}
\hline & \multicolumn{1}{c}{ WMD $\mathbf{( 9 5 \%}$ CI) } \\
\hline Non-operative treatment & $4.70(1.21,7.83)$ & $6.71(3.20,10.39)$ \\
$-4.70(-7.83,-1.21)$ & Plate fixation & $2.05(0.30,4.64)$ \\
$-6.71(-10.39,-3.20)$ & $-2.05(-4.64,-0.30)$ & Intramedullary pin fixation \\
\hline
\end{tabular}

Notes: Comparison between treatments should be read from column to row. WMD, weighted mean difference; 95\% CI, 95\% confidence intervals.

Table 3: Weighted mean difference and $95 \%$ confidence intervals of three treatment modalities of clavicular fractures patients in terms of the Constant-Murley Score after 6 weeks, 3 months, 12 months and 24 months

WMD (95\% CI)

(a) 6 weeks

Non-operative treatment

$-9.43(-24.37,5.49)$

$-10.90(-29.25,5.90)$

(b) 3 months

Non-operative treatment

$-1.93(-7.26,2.95)$

$-4.43(-13.15,2.63)$

(c) 12 months

Non-operative treatment

$-1.69(-6.62,3.68)$

$-4.97(-12.37,2.61)$

(d) 24 months

Non-operative treatment

$-4.33(-9.99,1.47)$

$-3.57(-7.80,0.47)$
$9.43(-5.49,24.37)$

Plate fixation

$-1.44(-11.90,7.39)$

$1.93(-2.95,7.26)$

Plate fixation

$-2.43(-9.15,2.86)$

$1.69(-3.68,6.62)$

Plate fixation

$-3.29(-8.62,2.08)$

$4.33(-1.47,9.99)$

Plate fixation

$0.77(-3.35,4.75)$
$10.90(-5.90,29.25)$

$1.44(-7.39,11.90)$

Intramedullary pin fixation

$4.43(-2.63,13.15)$

$2.43(-2.86,9.15)$

Intramedullary pin fixation

$4.97(-2.61,12.37)$

$3.29(-2.08,8.62)$

Intramedullary pin fixation

$3.57(-0.47,7.80)$

$-0.77(-4.75,3.35)$

Intramedullary pin fixation

Notes: Comparison between treatments should be read from column to row. WMD, weighted mean difference; $95 \% \mathrm{CI}, 95 \%$ confidence intervals.

Table 4: SUCRA values of three treatment modalities of clavicular fractures patients in terms of the Constant-Murley Score after five periods

\begin{tabular}{lccccc}
\hline \multirow{2}{*}{\multicolumn{1}{c}{ Treatments }} & \multicolumn{5}{c}{ SUCRA values } \\
\cline { 2 - 6 } & $\mathbf{6}$ weeks & 3 months & 6 months & 12 months & 24 months \\
\hline Non-operative treatment & 0.085 & 0.125 & 0.005 & 0.165 & 0.367 \\
Plate fixation & 0.635 & 0.490 & 0.500 & 0.430 & $\mathbf{0 . 8 6 7}$ \\
Intramedullary pin fixation & $\mathbf{0 . 7 8 0}$ & $\mathbf{0 . 8 8 5}$ & $\mathbf{0 . 9 8 5}$ & $\mathbf{0 . 9 1 0}$ & 0.767 \\
\hline
\end{tabular}

Notes: SUCRA, surface under the cumulative ranking curves.

primary treatment for $\mathrm{CF}$, mainly because the outcomes of non-operative treatment are inferior [1]. As a type of operative treatment, plate fixation provides the advantage of stable bony fixation with an instrument, which is kept away from potentially risky infraclavicular structures.
This poses minimal risk of implant prominence problems and results in fewer complications, early healing, and a rapid and complete return to normal function [28]. Intramedullary pin fixation, as a minimally invasive alternative for non-operative treatment, avoids many of the 
problems that occur during non-operative treatment [29]. Intramedullary pin fixation offers the benefits of fracture fixation with smaller incisions than traditional plate fixation, the ability to remove the implant via a similarly small incision with the patient under local anesthesia, and largely avoiding soft-tissue stripping at the site of fracture [30]. In accordance with our results, a previous study has reported better results and fewer complications with intramedullary pin fixation compared with both nonoperative treatment and plate fixation [31].

Our study here also suggested that compared with plate fixation, intramedullary pin fixation had a better efficacy in treating CF patients in terms of CMS. For modern plate fixation, the application of a $3.5 \mathrm{~mm}$ reconstruction plating at the anteroinferior site permits adequate fixation of the lateral fragment and maximum fracture stability [32] because it's easy to contour the plate to match the $\mathrm{S}$ shape of the clavicle compared to other older plates. Additionally, plate fixation has a low incidence of implant failure and nonunion, and avoids risk to the vital structures bellow the clavicle [22]. Despite these positive aspects, many complications have been reported for plate fixation in the treatment of mid-shaft CF. Usual complications include plate loosening, plate breakage, plate angulation, wound infection, nonunion and re-fracture after plate removal [33]. Even though plate fixation provides better biomechanics than intramedullary pin fixation because it is more resistant to torsional forces and bending, it involves greater exposure and extensive soft tissue stripping, which may impact fracture healing and elevate the risk of infection [34]. In contrast, a metaanalysis concluded that intramedullary pin fixation had a much lower rate of infection and nonunion than plate fixation due to lessened damages to blood supply during surgery $[35,36]$. The main reason for the differences was that plate insertion causes more extensive damage to the periosteum as well as the surrounding soft tissues than intramedullary rod insertion. Furthermore, a plate might frequently require removal if inserted on the surface above the clavicle due to its gross prominence over skin [37]. All the available evidence suggests that intramedullary pin fixation is the optimal treatment for mid-shaft CF patients. Further confirming our results, the SUCRA values of most of follow-up periods showed the highest SUCRA value

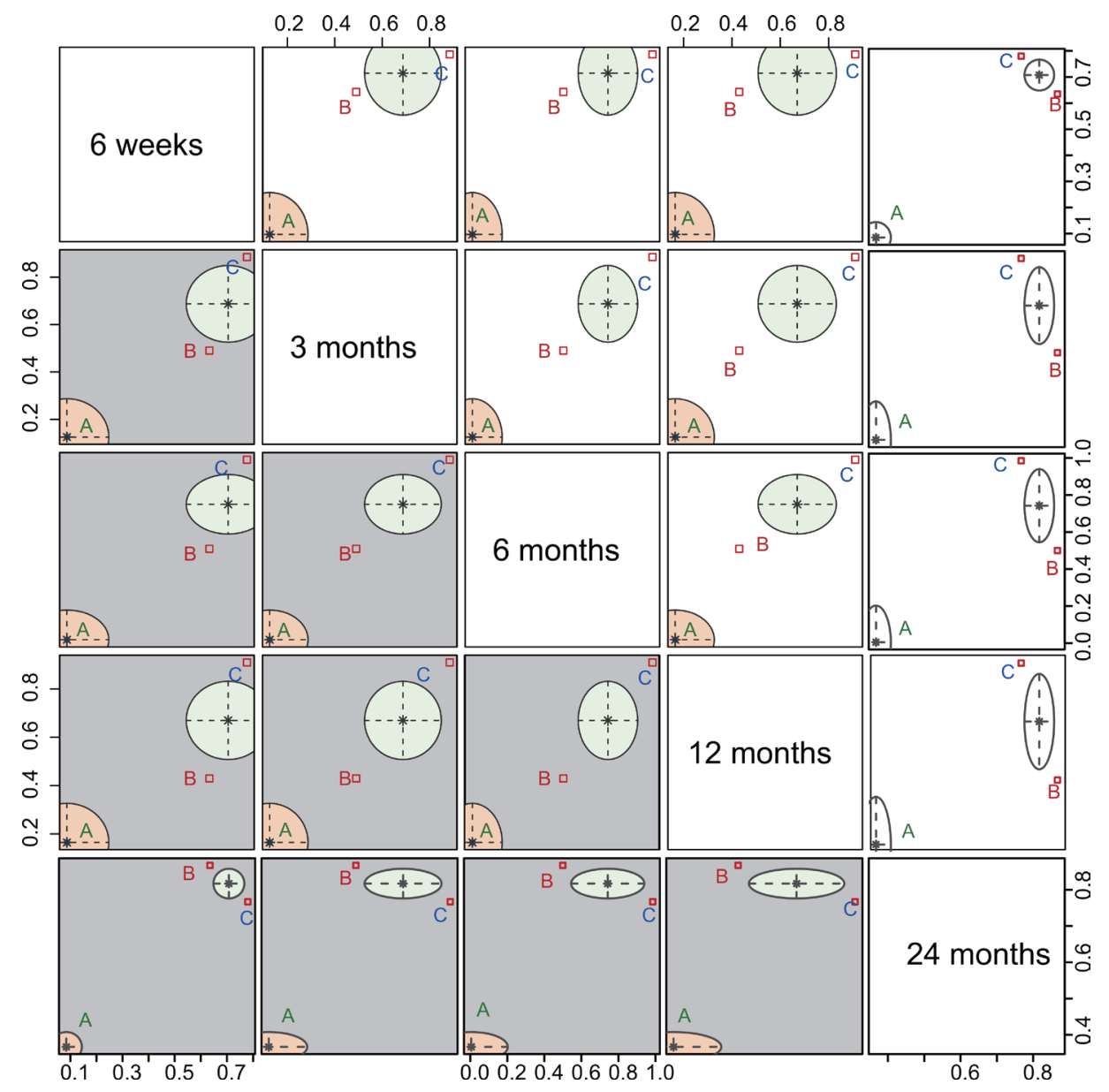

Figure 5: Plot of cluster analysis based on the SUCRA values with respect to CMS follow-up time. The follow-up times were six weeks, three months, six months, 12 months and 24 months. (A) Non-operative treatment. (B) Plate fixation. (C) Intramedullary pin fixation. CMS, Constant-Murley Score; SUCRA, surface under the cumulative ranking curve. 
for intramedullary pin fixation, followed by plate fixation and non-operative treatment. We measured no differences between the efficacies of the three mid-shaft CF treatments analyzed in pairwise comparisons with respect to CMS followed-up for six weeks, three months, 12 months and 24 months. The reasons might be: 1) small sample size; 2) limited number of studies meeting our criteria; 3) six weeks and three months might be too early to compare the efficacies of three treatments analyzed; and 4), 12 months and 24 months are both long enough to allow for completely wound healing, making any difference between treatments more difficult to detect. Therefore, our conclusion needs to be further confirmed based on high-quality RCT studies with more detailed and complete information.

Indeed, our study also suffered from several limitations: (1) our network meta-analysis included only 11 studies, a limited number that might reduce the reliability of our results. However, all the studies included were consistent with the purpose of our analysis since they were RTCs with high quality. (2) Only CMS was used to measure shoulder function in CF patients; we did not consider other scoring methods due to incomplete data. (3) Complications indexes were not analyzed in our network meta-analysis. Of note, Jia Wang et al. conducted another network meta-analysis in terms of nonunion rate and infection rate [38]. These limitations might preclude our results from being generalized. Nonetheless, our network meta-analysis has several strong points. First, we performed a systematic and exhaustive literature search to identify all relevant trials to make sure that all available and pertinent data were included. Second, we compared interventions indirectly when no head-to-head trial existed, to more precise estimate efficacy by evaluating both direct and indirect comparisons. Third, our integration of the latest published evidence provides new insights into treatment procedures to improve shoulder function of midshaft CF patients.

In summary, our current network meta-analysis provides evidence that intramedullary pin fixation is the optimal treatment for CF patients among three inventions, since it improves the CMS of CF patients compared to the other two procedures analyzed.

\section{MATERIALS AND METHODS}

\section{Literature search}

We searched electronic literature databases using Embase, Cochrane Library and PubMed (last updated search in April 2017) to identify studies relevant to three surgical procedures in CF. A combination of keywords and free words were used to retrieve studies relevant to the topic of interest, including clavicular fracture, treatment, plate fixation and intramedullary pin fixation. We also manually searched related bibliographies to identify studies that were missed in the electronic search.

\section{Inclusion and exclusion criteria}

The literature was systematically reviewed according to the following criteria: (1) study design: randomized controlled trail (RCT); (2) interventions: nonoperative treatment, plate fixation and intramedullary pin fixation; (3) study subject: clinically and radiologically diagnosed CF patients; (4) end outcomes: the CMS. The exclusion criteria included: (1) studies with insufficient data; (2) non-RCTs; (3) duplicated publications; (4) nonhuman studies and (5) abstracts, systematic reviews, or meeting proceedings.

\section{Data extraction and quality assessment}

All data from eligible trials were extracted independently by two investigators using a standard form, and any disagreements were resolved by reexamination of all items and reaching a consensus among several investigators. The methodological quality of the included RCTs was evaluated using Physiotherapy Evidence Database (PEDro) scale by two or more investigators [39]. The total scores of PEDro are 11 points, which is divided into high quality (scored $\geq$ four points) and low quality (scored $<$ four points) [40].

\section{Statistical analysis}

Firstly, we conducted traditional meta-analysis for paired comparison of direct evidence using the Meta package of R.3.2.1 software. We calculated the pooled estimates of weighted mean differences (WMDs) with corresponding $95 \%$ credible intervals (CrIs) of five periods of the CMS. We used chi-square and $I$-square tests to assess heterogeneity among the studies [41]. Afterwards, we utilized the network installation package of R.3.2.1 software to draw network diagram. In such diagrams, the nodes correspond to a variety of interventions, the node size corresponds to the sample size, and the thickness of lines corresponds to the number of enrolled studies. Additionally, gemtc installation package of R.3.2.1 software was used for network meta-analysis. In a Bayesian setting, the package gemtc offers a comprehensive set of tools to perform network meta-analysis. The four common outcome types, namely binary, continuous, count or survival, were used for the input of Arm- or contrast-level network data. As first described by Lu and Ades, gemtc modeled relative effects (e.g., log-odds ratio), which fitted a generalized linear model (GLM) under the Bayesian framework through connections to JAGS, OpenBUGS or WinBUGS [42]. This analysis has been further extended by others $[43,44]$. In a previous study, we conducted a 
random-effects network meta-analysis within a Bayesian framework using Markov Chain Monte Carlo (MCMC) in OpenBUGS 3.2.2 [45]. Here, comparative WMDs are reported with their respective $95 \%$ CrIs. In our present study we utilized the node-splitting method to evaluate the consistency between direct and indirect evidence, and to select the consistency or inconsistency model based on the results [46]. To assist in the interpretation of WMDs, we calculated the probability of each treatment being the most effective or safest based on a Bayesian approach using probability values summarized as surface under the cumulative ranking curve (SUCRA). The larger the SUCRA value, the better the rank of the intervention $[47,48]$. All analyses were conducted with R 3.2.1.

\section{ACKNOWLEDGMENTS}

We send our sincere gratitude to the reviewers for their kind comments.

\section{CONFLICTS OF INTEREST}

No conflicts of interest to declare.

\section{FUNDING}

This study was supported by the Shenzhen Science and Technology Innovation Project (JCYJ20150403101028191 and JCYJ20150403101146282), the Provincial Science Foundation of Hunan (No. 2015JJ3139) and China Scholarship Council (student ID: 201606375101).

\section{REFERENCES}

1. Smekal V, Irenberger A, Struve $\mathrm{P}$, Wambacher $\mathrm{M}$, Krappinger D, Kralinger FS. Elastic stable intramedullary nailing versus nonoperative treatment of displaced midshaft clavicular fractures-a randomized, controlled, clinical trial. J Orthop Trauma. 2009; 23:106-112.

2. Wang N, Zhang H, Yao Q, Wang Y, Dai S, Yang X. TGFBI promoter hypermethylation correlating with paclitaxel chemoresistance in ovarian cancer. J Exp Clin Cancer Res. 2012; 31:6.

3. d'Heurle A, Le T, Grawe B, Casstevens EC, Edgington J, Archdeacon MT, Wyrick J. Perioperative risks associated with the operative treatment of clavicle fractures. Injury. 2013; 44:1579-1581.

4. Strauss BJ, Carey TP, Seabrook JA, Lim R. Pediatric clavicular fractures: assessment of fracture patterns and predictors of complicated outcome. J Emerg Med. 2012; 43:29-35.

5. Duan X, Zhong G, Cen S, Huang F, Xiang Z. Plating versus intramedullary pin or conservative treatment for midshaft fracture of clavicle: a meta-analysis of randomized controlled trials. J Shoulder Elbow Surg. 2011; 20:1008-1015.
6. Oh JH, Kim SH, Lee JH, Shin SH, Gong HS. Treatment of distal clavicle fracture: a systematic review of treatment modalities in 425 fractures. Arch Orthop Trauma Surg. $2011 ; 131: 525-533$.

7. Kim KC, Shin HD, Cha SM. Surgical treatment of displaced medial clavicle fractures using a small T-shaped plate and tension band sutures. Arch Orthop Trauma Surg. 2011; 131:1673-1676.

8. Krishna R, Mongia AK. Outcome of surgical and conservative management of fractures of the middle-third of the clavicle. Indian Journal of Orthopaedics Surgery. 2015; 1:87-92.

9. Khan LA, Bradnock TJ, Scott C, Robinson CM. Fractures of the clavicle. J Bone Joint Surg Am. 2009; 91: 447-460.

10. Judd DB, Pallis MP, Smith E, Bottoni CR. Acute operative stabilization versus nonoperative management of clavicle fractures. Am J Orthop (Belle Mead NJ). 2009; 38:341-345.

11. Pujalte GG, Housner JA. Management of clavicle fractures. Curr Sports Med Rep. 2008; 7:275-280.

12. Liu PC, Chien SH, Chen JC, Hsieh CH, Chou PH, Lu CC. Minimally invasive fixation of displaced midclavicular fractures with titanium elastic nails. J Orthop Trauma. 2010; 24:217-223.

13. Denard PJ, Koval KJ, Cantu RV, Weinstein JN. Management of midshaft clavicle fractures in adults. Am J Orthop (Belle Mead NJ). 2005; 34:527-536.

14. Hsu TL, Hsu SK, Chen HM, Wang ST. Comparison of hook plate and tension band wire in the treatment of distal clavicle fractures. Orthopedics. 2010; 33:879.

15. Wu K, Chang CH, Yang RS. Comparing hook plates and Kirschner tension band wiring for unstable lateral clavicle fractures. Orthopedics. 2011; 34:e718-723.

16. Peruzzi M, De Luca L, Thomsen HS, Romagnoli E, D'Ascenzo F, Mancone M, Sardella G, Lucisano L, Abbate A, Frati G, Biondi-Zoccai G. A network metaanalysis on randomized trials focusing on the preventive effect of statins on contrast-induced nephropathy. Biomed Res Int. 2014; 2014:213239.

17. Sutton A, Ades AE, Cooper N, Abrams K. Use of indirect and mixed treatment comparisons for technology assessment. Pharmacoeconomics. 2008; 26:753-767.

18. Liao WC, Chien KL, Lin YL, Wu MS, Lin JT, Wang HP, Tu YK. Adjuvant treatments for resected pancreatic adenocarcinoma: a systematic review and network metaanalysis. Lancet Oncol. 2013; 14:1095-1103.

19. Lee YS, Lin CC, Huang CR, Chen CN, Liao WY. Operative treatment of midclavicular fractures in 62 elderly patients: knowles pin versus plate. Orthopedics. 2007; 30:959-964.

20. Lee YS, Huang HL, Lo TY, Hsieh YF, Huang CR. Surgical treatment of midclavicular fractures: a prospective comparison of Knowles pinning and plate fixation. Int Orthop. 2008; 32:541-545. 
21. Ferran NA, Hodgson P, Vannet N, Williams R, Evans RO. Locked intramedullary fixation vs plating for displaced and shortened mid-shaft clavicle fractures: a randomized clinical trial. J Shoulder Elbow Surg. 2010; 19:783-789.

22. Assobhi JE. Reconstruction plate versus minimal invasive retrograde titanium elastic nail fixation for displaced midclavicular fractures. J Orthop Traumatol. 2011; 12:185-192.

23. Smekal V, Irenberger A, Attal RE, Oberladstaetter J, Krappinger D, Kralinger F. Elastic stable intramedullary nailing is best for mid-shaft clavicular fractures without comminution: results in 60 patients. Injury. 2011; 42:324-329.

24. Virtanen KJ, Remes V, Pajarinen J, Savolainen V, Bjorkenheim JM, Paavola M. Sling compared with plate osteosynthesis for treatment of displaced midshaft clavicular fractures: a randomized clinical trial. J Bone Joint Surg Am. 2012; 94:1546-1553.

25. Narsaria N, Singh AK, Arun GR, Seth RR. Surgical fixation of displaced midshaft clavicle fractures: elastic intramedullary nailing versus precontoured plating. J Orthop Traumatol. 2014; 15:165-71.

26. Saha P, Datta P, Ayan S, Garg AK, Bandyopadhyay U, Kundu S. Plate versus titanium elastic nail in treatment of displaced midshaft clavicle fractures: A comparative study. Indian J Orthop. 2014; 48:587-593.

27. Melean PA, Zuniga A, Marsalli M, Fritis NA, Cook ER, Zilleruelo M, Alvarez C. Surgical treatment of displaced middle-third clavicular fractures: a prospective, randomized trial in a working compensation population. J Shoulder Elbow Surg. 2015; 24:587-592.

28. Collinge C, Devinney S, Herscovici D, DiPasquale T, Sanders R. Anterior-inferior plate fixation of middle-third fractures and nonunions of the clavicle. J Orthop Trauma. 2006; 20:680-686.

29. van der Meijden OA, Gaskill TR, Millett PJ. Treatment of clavicle fractures: current concepts review. J Shoulder Elbow Surg. 2012; 21:423-429.

30. van der Meijden OA, Houwert RM, Hulsmans M, Wijdicks FJ, Dijkgraaf MG, Meylaerts SA, Hammacher ER, Verhofstad MH, Verleisdonk EJ. Operative treatment of dislocated midshaft clavicular fractures: plate or intramedullary nail fixation? A randomized controlled trial. J Bone Joint Surg Am. 2015; 97:613-619.

31. Canadian Orthopaedic Trauma S. Nonoperative treatment compared with plate fixation of displaced midshaft clavicular fractures. A multicenter, randomized clinical trial. J Bone Joint Surg Am. 2007; 89:1-10.

32. Werner SD, Reed J, Hanson T, Jaeblon T. Anatomic relationships after instrumentation of the midshaft clavicle with 3.5-mm reconstruction plating: an anatomic study. J Orthop Trauma. 2011; 25: 657-660.

33. Wijdicks FJ, Van der Meijden OA, Millett PJ, Verleisdonk EJ, Houwert RM. Systematic review of the complications of plate fixation of clavicle fractures. Arch Orthop Trauma Surg. 2012; 132:617-625.

34. Smith SD, Wijdicks CA, Jansson KS, Boykin RE, Martetschlaeger F, de Meijer PP, Millett PJ, Hackett TR.
Stability of mid-shaft clavicle fractures after plate fixation versus intramedullary repair and after hardware removal. Knee Surg Sports Traumatol Arthrosc. 2014; 22:448-455.

35. Zhu Y, Tian Y, Dong T, Chen W, Zhang F, Zhang Y. Management of the mid-shaft clavicle fractures using plate fixation versus intramedullary fixation: an updated metaanalysis. Int Orthop. 2015; 39:319-328.

36. Renfree T, Conrad B, Wright T. Biomechanical comparison of contemporary clavicle fixation devices. J Hand Surg Am. 2010; 35:639-644.

37. Ouyang H, Xiong J, Xiang P, Cui Z, Chen L, Yu B. Plate versus intramedullary nail fixation in the treatment of humeral shaft fractures: an updated meta-analysis. J Shoulder Elbow Surg. 2013; 22:387-395.

38. Wang J, Meng $\mathrm{XH}$, Guo $\mathrm{ZM}$, Wu $\mathrm{YH}$, Zhao JG. Interventions for treating displaced midshaft clavicular fractures: a Bayesian network meta-analysis of randomized controlled trials. Medicine (Baltimore). 2015; 94:e595.

39. Maher CG, Sherrington C, Herbert RD, Moseley AM, Elkins M. Reliability of the PEDro scale for rating quality of randomized controlled trials. Phys Ther. 2003; 83:713-721.

40. Ferreira LL, Valenti VE, Vanderlei LC. Chest physiotherapy on intracranial pressure of critically ill patients admitted to the intensive care unit: a systematic review. Rev Bras Ter Intensiva. 2013; 25:327-333.

41. Chen LX, Li YL, Ning GZ, Li Y, Wu QL, Guo JX, Shi HY, Wang XB, Zhou Y, Feng SQ. Comparative efficacy and tolerability of three treatments in old people with osteoporotic vertebral compression fracture: a network meta-analysis and systematic review. PLoS One. 2015; 10:e0123153.

42. $\mathrm{Lu} \mathrm{G}, \mathrm{Ades} \mathrm{AE}$. Combination of direct and indirect evidence in mixed treatment comparisons. Stat Med. 2004; 23:3105-3124.

43. Dias S, Sutton AJ, Ades AE, Welton NJ. Evidence synthesis for decision making 2: a generalized linear modeling framework for pairwise and network meta-analysis of randomized controlled trials. Med Decis Making. 2013; 33:607-617.

44. Dias S, Welton NJ, Caldwell DM, Ades AE. Checking consistency in mixed treatment comparison meta-analysis. Stat Med. 2010; 29:932-944.

45. Lunn D, Spiegelhalter D, Thomas A, Best N. The BUGS project: Evolution, critique and future directions. Stat Med. 2009; 28: 3049-3067.

46. Zhu GQ, Shi KQ, Huang S, Wang LR, Lin YQ, Huang GQ, Chen YP, Braddock M, Zheng MH. Systematic review with network meta-analysis: the comparative effectiveness and safety of interventions in patients with overt hepatic encephalopathy. Aliment Pharmacol Ther. 2015; 41:624-635.

47. Chaimani A, Higgins JP, Mavridis D, Spyridonos P, Salanti G. Graphical tools for network meta-analysis in STATA. PLoS One. 2013; 8:e76654.

48. Salanti G, Ades AE, Ioannidis JP. Graphical methods and numerical summaries for presenting results from multipletreatment meta-analysis: an overview and tutorial. J Clin Epidemiol. 2011; 64:163-171. 